\title{
Ganz osteotomy for treatment of hip dysplasia through intra-pelvic approach. Early results
}

\author{
Ahmed M. Saied, Bassam Abouelnas, Wael El-Adl, Rene Verdonk, Khaled Zaghloul \\ From the Department of Orthopaedic surgery and Traumatology, Mansoura University Hospital, Mansoura, Egypt
}

\begin{abstract}
Ganz periacetabular osteotomy $(\mathrm{PAO})$ is a technically demanding surgical procedure. It requires cutting around the acetabulum to mobilize it under fluoroscopic control. The radiolucent table and good quality imaging are mandatory to perform this osteotomy in a safe way. Modification of Ganz osteotomy was developed a with minimal soft tissue exposure using intra-pelvic approach which allows direct visualization of the quadrilateral plate. The purpose of the present study was to review the early results in the initial group of patients who had this procedure. The Ganz PAO was performed on 8 cases painful dysplastic hips, using the intra-pelvic approach through the Pfannenstiel incision. All of the osteotomies were performed under fluoroscopic control and direct visualizing the osteotomy site from the same incision. The acetabular fragment was medialized and redirected anterolaterally then fixed with 3 screws. The pre-operative Harris hip score mean was 66.8 and improved to be 92.7 ( $p$ value $<0.0005$ ) and this was statistically significant. Radiologically the CEA improved in the pre-operative $\mathrm{X}$-ray from mean of 13.12 degree to 28.37 degrees ( $p$ value $<0.0005$ ) and this was statistically significant. Painful dysplastic hips should be treated before function becomes seriously impaired. The Ganz osteotomy through an intra-pelvic approach, can be done with minimal exposure to radiation in a relatively short time.
\end{abstract}

Keywords: dysplasia; hip; Ganz; Stoppa; osteotomy; periacetabular.

Declaration of conflicting interests: The author(s) declared no potential conflicts of interest with respect to the research, authorship, and/or publication of this article.

Funding:The author(s) received no financial support for the research, authorship, and/or publication of this article.

\section{INTRODUCTION}

Ganz Periacetabular osteotomy (PAO) is a redirectional osteotomy done for the management of hip dysplasia (1). It is a hip preserving procedure by which hip replacement can be delayed and possibly avoided (2). It is all about changing the shearing force due to the rim loading of the head to a compressive force by changing the way the head is loaded. By freeing the acetabulum segment the cavity can be placed in the desired position avoiding the effect of two strong ligaments (sacro-spinous and sacro-tubrous ligaments) (3).

Ganz et al (4) described the Ganz PAO which is generally accepted as a technically demanding osteotomy and not free from complication. Most of these complications occurred because it is an image guided osteotomy with perioperative limited visualization especially the ischial cut

\footnotetext{
Ahmed M. Saied ${ }^{1}$, MD

Bassam Abouelnas ${ }^{1}, \mathrm{MD}$

Wael El-Adl', MD

Rene Verdonk ${ }^{2}, \mathrm{MD}, \mathrm{PhD}$

- Khaled Zaghloul ${ }^{1}$, MD

${ }^{1}$ Department of Orthopaedic Surgery and Traumatology, Mansoura University Hospital Mansoura, Egypt.

${ }^{2}$ Prof em orthopedics and Traumatology, Consultant univ hosp Erasmus, Brussels, Belgium.

Correspondence : Ahmed M Saied, Mansoura University Hospital, 35511 Mansoura, Egypt. Phone: 00201022266999. Email : ahmed_saied@mans.edu.eg

- 2021, Acta Orthopædica Belgica.
} 
and the posterior column cut. The most common complication during the surgery is penetration of the osteotome into the hip joint cavity, some authors have reported a $2.7 \%$ rate for this complication, which occurred due to the inability to visualize the quadrilateral surface (5).

Ganz PAO can be done through the classic smith Peterson approach with adding osteotomy of the anterior superior iliac spine (ASIS). Trying to preserve the muscle integrity; a rectus preserving Ganz PAO is also reported with good recovery of muscle power post operatively (6). Several incision modifications have been introduced because of the vigorous muscle dissection and wide scar in the classic Smith Peterson incision, which was originally used in PAO $(7,8,9,10,11)$. All of those approaches entitle doing the ischial and posterior column cut under the guidance of image intensifier increasing exposure of the surgeon and the patient to irradiation.

Intrapelvic modified Stoppa approach was used in this study to minimize exposure to radiation. It was first mentioned in 1993 by Cole et al. (12) for the management of anterior acetabular column fractures.

Two Cadaveric studies were conducted by Mehmet et al and Turgut et al. $(13,14)$ and concluded that Ganz PAO can be done safely utilizing the intrapelvic modified Stoppa approach. It provides minimal dissection of muscles and as a result of direct visualization of the quadrilateral surface through the exposure, the use of image intensifier is decreased.

\section{MATERIAL AND METHODS}

After approval of the institutional review board (IRB), this study was conducted from October 2016 to October 2018 on 8 cases of hip dysplasia 6 females and 2 males. The age range from 16-32 years with a mean 21.1 years. All patients presented with hip pain related to activity but 2 cases had mechanical symptoms; catching or locking with positive anterior impingement test. All patients were examined and evaluated by Plain $\mathrm{x}$ ray AP, frog lateral and False profile views. The center edge angle was measured pre-and post-surgery as well

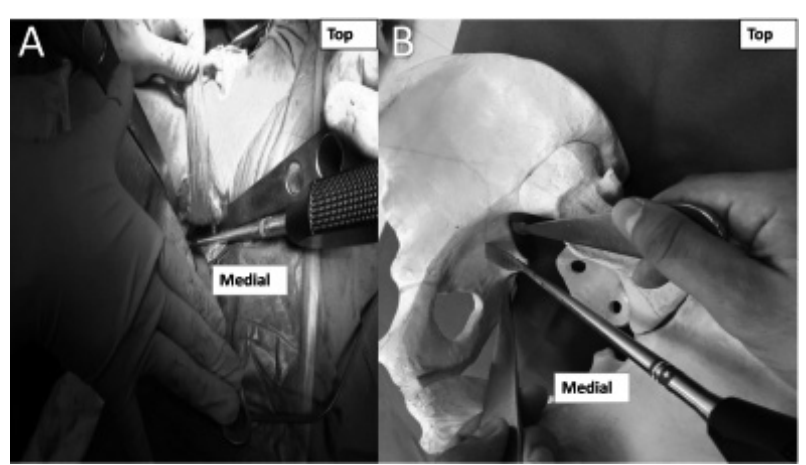

Figure 1. - (A) Intraoperative photo showing the application of the osteotome through the Stoppa window to execute the ischial and posterior column cuts. (B) Demonstration on pelvic model to mimic the position of the osteotome and Homans as in (A).

we evaluated our patients with Harris hip score preand 6 months post-op.

The technique described by Cole (12) et al used the modified Stoppa approach to treat acetabular fractures. We used it to perform the Ganz PAO as originally described. Two centimeters $(\mathrm{cm})$ above the symphysis pubis a midline $10 \mathrm{~cm}$ transverse incision was made. The linea alba is identified and cleavage between both rectus abdominis muscle is identified, we did not need to release the rectus muscle from the pubic insertion. The abdominal muscles were bluntly dissected after incision of the fascia transversalis then using a blunt retractor the peritoneum was retracted craniomedially. The corona mortis was identified and ligated carefully. The iliopectineal fascia was incised and the periosteum was elevated till a blunt retractor was inserted into the greater sciatic notch. The obturator nerve was identified and preserved in all cases. By flexing the hip and periosteal dissection a pointed Homman retractor is applied in the lesser sciatic notch.

The first osteotomy to be done is the ischial osteotomy under direct vision and image guidance at the top part of the obturator foramen. (Figure 1).

The next osteotomy is the pubic cut which is very accessible with no much retraction. Then we open a $5-\mathrm{cm}$ incision on the iliac crest to execute the iliac osteotomy; no need for the ASIS osteotomy. The posterior column osteotomy is done by image and visual control. (Figure 2) 


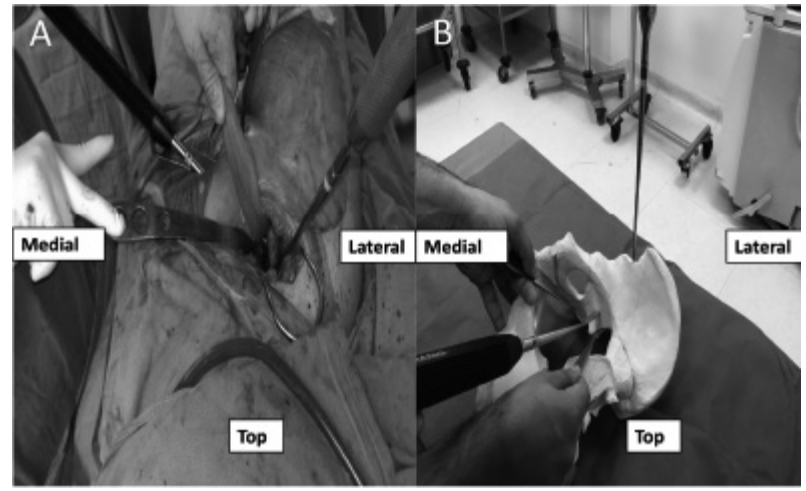

Figure 2. - (A) Intraoperative photo showing the application of one osteotome through the iliac window to execute the iliac cut and another osteotome through the Stoppa window to complete the posterior column cut. (B) Demonstration on pelvic model to mimic the position of the osteotomes and Homans as in (A).

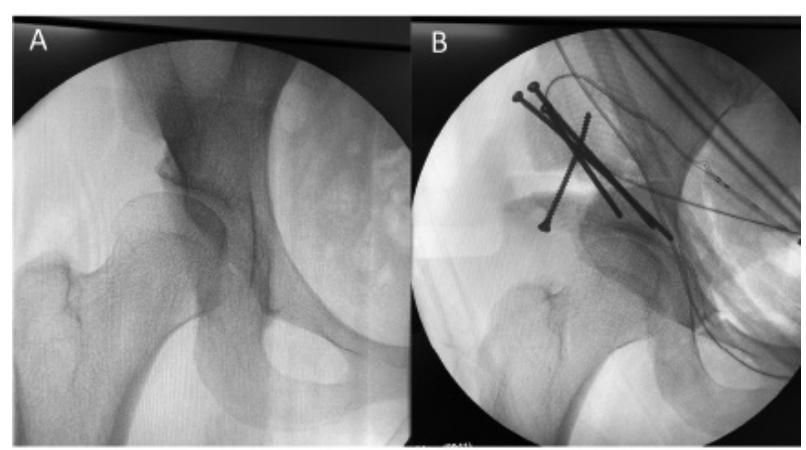

Figure 3. - (A) Preoperative fluoroscopy of the right hip. (B) Postoperative fluoroscopy of the right hip.

Because of the visual control when doing the osteotomy, we rarely need to revisit the osteotomy site as used to be done in the original technique where the completion of the osteotomies is checked after failure to move the acetabular fragment. Through the iliac incision mobilization and fixation of the fragment is done with $3.5 \mathrm{~mm}$ screws as has been described in the original technique. We illustrated a case example with follow up 3 months (Figures 3, 4, 5, 6).

\section{RESULTS}

We evaluated our patients clinically using the Harris hip score pre-and 6 months post-operative. The pre-operative Harris hip score mean was 66.8 and improved to be 92.7 ( $\mathrm{p}$ value $<0.0005$ ) and this

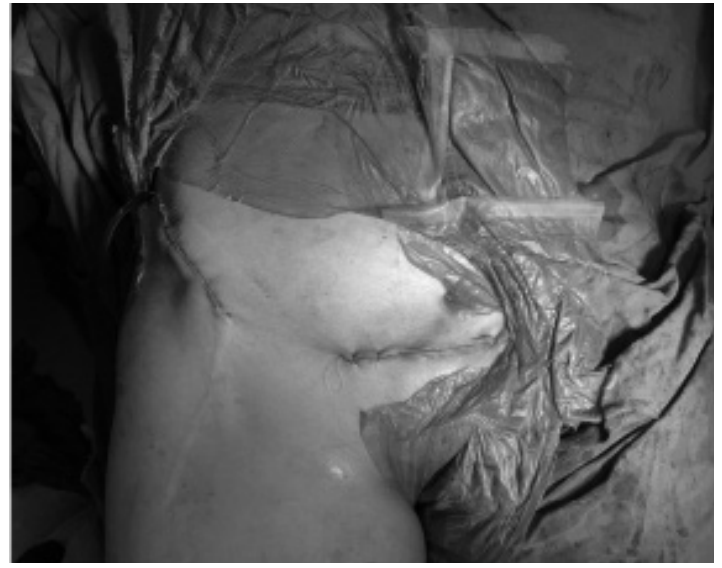

Figure 4. - Postoperative photo showing closure of the Stoppa scar and iliac scar.

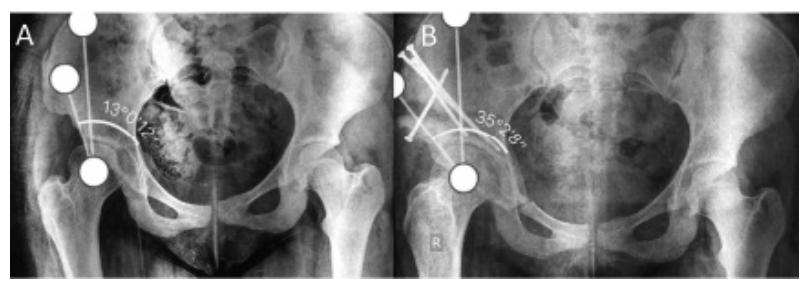

Figure 5. - (A) Preoperative X-ray showing center edge angle 13 degree. (B). Preoperative X-ray showing center edge angle 35 degree.

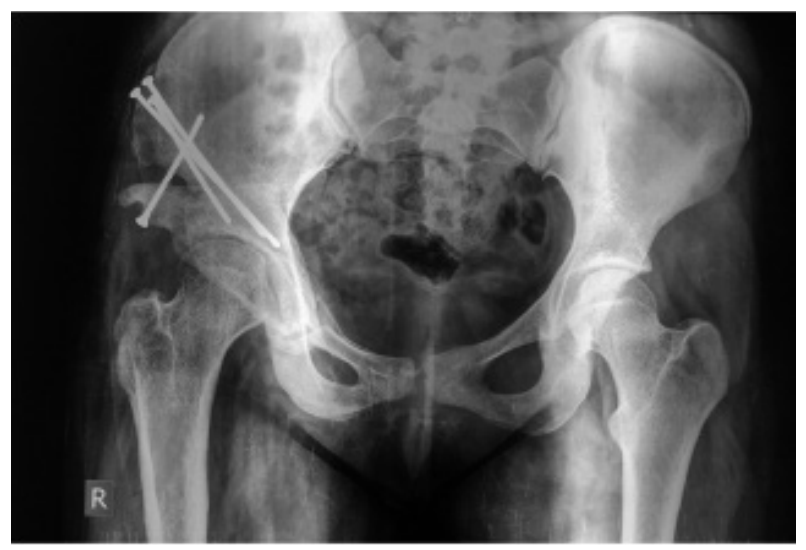

Figure 6. - Follow up X-ray 3 months postoperative showing good achievement of coverage and union.

was statistically significant. Radiologically the CEA improved in the pre-operative X-ray from mean of 13.12 degree to 28.37 degrees ( $p$ value $<0.0005$ ) and this was statistically significant. The mean follow up period 10.8 months. The operative time 
Table I. — Summary of results

\begin{tabular}{|l|c|c|c|c|c|c|c|c|c|c|}
\hline & Age & Gender & CEA pre & Harris pre & FU & CEA post & Harris post & Surgery time & EBL & X-ray dose \\
\hline $\mathbf{1}$ & 17 & F & 15 & 75 & 14 & 33 & 90 & $70 \mathrm{~min}$ & $200 \mathrm{cc}$ & $40 \mathrm{sec}$ \\
\hline $\mathbf{2}$ & 22 & F & 14 & 65 & 13 & 26 & 89 & $80 \mathrm{~min}$ & $200 \mathrm{cc}$ & $55 \mathrm{sec}$ \\
\hline $\mathbf{3}$ & 18 & F & 13 & 60 & 12 & 35 & 95 & $65 \mathrm{~min}$ & $250 \mathrm{cc}$ & $45 \mathrm{sec}$ \\
\hline $\mathbf{4}$ & 21 & M & 13 & 75 & 11 & 32 & 92 & $70 \mathrm{~min}$ & $250 \mathrm{cc}$ & $60 \mathrm{sec}$ \\
\hline $\mathbf{5}$ & 16 & F & 10 & 70 & 11 & 24 & 95 & $60 \mathrm{~min}$ & $300 \mathrm{cc}$ & $45 \mathrm{sec}$ \\
\hline $\mathbf{6}$ & 32 & F & 14 & 65 & 10 & 29 & 92 & $65 \mathrm{~min}$ & $100 \mathrm{cc}$ & $40 \mathrm{sec}$ \\
\hline $\mathbf{7}$ & 25 & M & 10 & 65 & 8 & 25 & 94 & $60 \mathrm{~min}$ & $250 \mathrm{cc}$ & $65 \mathrm{sec}$ \\
\hline $\mathbf{8}$ & 18 & F & 16 & 60 & 8 & 23 & 95 & $65 \mathrm{~min}$ & $100 \mathrm{cc}$ & $45 \mathrm{sec}$ \\
\hline
\end{tabular}

was 66.8 minutes and the estimated blood loss EBL mean was $206.2 \mathrm{cc}$. The $\mathrm{C}$-arm was used and the mean time was 49.3 seconds. (Table-1)

\section{DISCUSSION}

In this study, we evaluated the safety and feasibility of the Ganz PAO with the help of the intrapelvic approach. Our early results indicated that the Ganz PAO can be done in a safe way due to direct visualization of the quadrilateral plate as it also reduces the irradiation exposure. To our knowledge this is the first clinical study to implement the intrapelvic approach in Ganz PAO.

Ganz PAO has good results in treating acetabular dysplasia $(15,4,16,17,18)$. Many surgical approaches for Ganz PAO have been described; the most frequently used is the Smith Petersen approach (4).

There is a high risk of intrapelvic vascular injury during Ganz PAO (19). Excessive arterial bleeding requiring embolization was reported in a patient with a prior Ganz PAO (5). Kambe et al. (20) discussed the increased risk for vascular injury by measuring the distance between the superior pubic ramus and the obturator artery, it was between 27.2 to $33.4 \mathrm{~mm}$.

Wall et al. (21) reported that the obturator nerve and artery passes between 4 and $8 \mathrm{~mm}$ posteriorly during superior pubic ramus osteotomy. In exposures made with a Smith Peterson incision, the obturator nerve is at risk along the course of the obturator foramen because the nerve passing immediately inferior cannot be relocated and may thus be damaged during pubic ramus osteotomy (4). By using modified Stoppa approach in our study, the full length of the obturator nerve could be identified and protected.

Ganz et al. (4) described chisel penetration to the joint cavity as the most severe complication of the procedure, occurring at a rate of $2.7 \%$. This occurred because the quadrilateral surface cannot be completely visualized and the osteotomies is done under image control (22). In a study by Shiramizu et al. (22) that aimed to minimize complications, they tried to prevent osteotome joint penetration by identifying landmarks in the quadrilateral area. With the intrapelvic approach, the acetabulum is seen from the medial aspect and the quadrilateral surface can be completely exposed.

Ganz PAO performed with the modified Stoppa approach may have better cosmetic results because a bikini can cover the incision scar. The length of the modified Stoppa incision may be similar to that of a Smith Petersen incision, but the Stoppa incision is parallel to the skin creases so healing is more physiologic and the procedure may result in less scarring than a classic incision would.

\section{CONCLUSION}

The early result of Ganz osteotomy using an intapelvic modified Stoppa approach in treatment of hip dysplasia is satisfactory, safe and decreases the amount of radiographic exposure. 


\section{REFERENCES}

1. Wenger DR, Bomar JD. Human hip dysplasia: evolution of current treatment concepts. J Orthop Sci. 2003; 8(2): 264-71.

2. Murphy SB, Ganz R, Müller ME. The prognosis in untreated dysplasia of the hip. A study of radiographic factors that predict the outcome. J Bone Joint Surg Am. 1995; 77(7): 985-9.

3. Ganz R, Leunig M. Osteotomy and the dysplastic hip: the Bernese experience. Orthopedics. 2002; 25(9): 945-6.

4. Ganz R, Klaue K, Vinh TS, Mast JW. Anew periacetabular osteotomy for the treatment of hip dysplasias: technique and preliminary results. 1988. Clin Orthop Relat Res. 2004; (418): 3-8.

5. Thawrani D, Sucato DJ, Podeszwa DA, DeLaRocha A. Complications Associated with the Bernese Periacetabular Osteotomy for Hip Dysplasia in Adolescents. $J$ Bone $J t$ Surgery-American Vol. 2010; 92(8): 1707-14.

6. Clohisy JC, Schutz AL, St. John L, Schoenecker PL, Wright RW. Periacetabular osteotomy: A systematic literature review. Clin Orthop Relat Res. 2009; 467(8): 2041-52.

7. Troelsen A, Elmengaard B, Søballe K. A New Minimally Invasive Transsartorial Approach for Periacetabular Osteotomy. J Bone Jt Surgery-Am. 2008; 90(3): 493-8.

8. Bernstein P, Thielemann F, Günther K-P. A modification of periacetabular osteotomy using a two-incision approach. Open Orthop J. 2007; 1(1): 13-8.

9. Ko J-Y, Wang C-J, Lin C-FJ, Shih C-H. Periacetabular osteotomy through a modified ollier transtrochanteric approach for treatment of painful dysplastic hips. $J$ Bone Joint Surg Am. 2002; 84-A(9): 1594-604.

10. Pajarinen J, Hirvensalo E. Two-incision technique for rotational acetabular osteotomy: good outcome in 35 hips. Acta Orthop Scand. 2003; 74(2): 133-9.

11. Bernstein P, Thielemann F, Günther K-P. A modification of periacetabular osteotomy using a two-incision approach. Open Orthop J. 2007; 1(1): 13-8.
12. Cole JD, Bolhofner BR. Acetabular fracture fixation via a modified Stoppa limited intrapelvic approach. Description of operative technique and preliminary treatment results. Clin Orthop Relat Res. 1994; (305): 112-23.

13. Elmadağ M, Uzer G, Yıldız F, Ceylan HH, Acar MA. Safety of modified Stoppa approach for Ganz periacetabular osteotomy: A preliminary cadaveric study. Acta Orthop Traumatol Turc. 2016; 50(4): 409-14.

14. Akgul T, Coskun O, Korkmaz M, Gurses I, Sen C, Gayretli O. A minimally invasive technique using a modified stoppa approach for periacetabular osteotomy: A preliminary cadaveric study. Indian J Orthop. 2017; 51(6): 687.

15. Murphy SB, Millis MB, Hall JE. Surgical correction of acetabular dysplasia in the adult. A Boston experience. Clin Orthop Relat Res. 1999; (363): 38-44.

16. Clohisy JC, Barrett SE, Gordon JE, Delgado ED, Schoenecker PL. Periacetabular Osteotomy in the Treatment of Severe Acetabular Dysplasia. JBJS Essent Surg Tech. 2006; os-88(1_suppl_1): 65-83.

17. Gillett CA. Bernese periacetabular osteotomy for hip dysplasia in young adults. AORN J. 2002; 75(4): 737-42, 744-7, 749-51; quiz 752, 754, 756-8.

18. Katz DA, Kim Y-J, Millis MB. Periacetabular osteotomy in patients with Down's syndrome. J Bone Joint Surg Br. 2005; 87-B(4): 544-7.

19. Inan M, Gokce A, Ustunkan F. Endoscopy-assisted periacetabular osteotomy: a preliminary cadaveric study. Clin Orthop Relat Res. 2008; 466(4): 862-70.

20. Kambe T, Naito M, Asayama I, Koga K, Fujisawa M, Yamaguchi T, et al. Vascular anatomy for rotational acetabular osteotomy: cadaveric study. J Orthop Sci. 2003; 8(3): 323-8.

21. Wall EJ, Kolata R, Roy DR, Mehlman CT, Crawford AH. Endoscopic pelvic osteotomy for the treatment of hip dysplasia. J Am Acad Orthop Surg.; 9(3): 150-6.

22. Shiramizu K, Naito M, Asayama I, Yatsunami M. A quantitative anatomic characterization of the quadrilateral surface for periacetabular osteotomy. Clin Orthop Relat Res. 2004; (418): 157-61. 